\title{
Healthy eating guidelines: Can it be more palatable and convenient for consumers?
}

Approximately 200 different food decisions are made in any one day verifying that eating, drinking and food choices are among the most frequent of daily human behaviours ${ }^{(1)}$. In order to understand or try to influence food choice decisions and behaviours, the attitudes and motivations underpinning this behaviour must be explored and understood ${ }^{(2,3)}$. Although dietary guidelines are evidence based, targeted and culturally appropriate; they fail to account for the impact of differing attitudes and motivations on food choice behaviour.

The aim of this research is to determine the impact of food choice attitudes and motivations on dietary behaviour and to demonstrate how this evidence can be used to enhance the targeting of dietary guidelines for health eating.

The National Adult Nutrition Survey collected data on the food and beverage consumption of 1500 Irish adults and alongside anthropometric measurements, socio-demographic and lifestyle data, physical activity. Food choice attitudes and motivations were measured by a questionnaire using a range previously validated constructs.

Analysis of the food choice motives showed that taste was the most important food choice motive for consumers followed by health and nutrition. As shown in the Table, those who rank taste and other motivations such as cost and convenient high have different dietary intakes compared to those who rank health and nutrition higher. Energy and percentage energy from fat is higher, and fruit and vegetable consumption is lower for those who rank taste as their primary motivation in food choice. A lower BMI and high fruit and veg intake was associated with higher nutrition ranking and lower cost ranking. Health as a primary motivation was associated with a lower BMI and higher fruit and vegetable consumption. Convenience motivation was associated with lower fruit and vegetable intakes.

\begin{tabular}{|c|c|c|c|c|c|c|c|c|c|c|}
\hline \multirow[b]{2}{*}{ Motive } & \multirow[b]{2}{*}{ Ranking } & \multirow[b]{2}{*}{$\%$} & \multicolumn{2}{|c|}{$\begin{array}{c}\text { EI } \\
\text { kcal d-1 }\end{array}$} & \multicolumn{2}{|c|}{$\%$ EI Fat } & \multicolumn{2}{|c|}{$\begin{array}{c}\text { BMI } \\
\mathrm{kg} \mathrm{m-2}\end{array}$} & \multicolumn{2}{|c|}{$\begin{array}{c}\text { Fruit \& veg } \\
\text { g d-1 }\end{array}$} \\
\hline & & & Mean & $\overline{\mathrm{SD}}$ & Mean & $\overline{\mathrm{SD}}$ & Mean & $\overline{\mathrm{SD}}$ & Mean & $\overline{\mathrm{SD}}$ \\
\hline \multirow[t]{2}{*}{ Taste } & $1 \mathrm{st} / 2 \mathrm{nd}$ & 54 & $2104^{a}$ & 659 & $35^{\mathrm{a}}$ & 5.9 & $26 \cdot 8$ & $4 \cdot 7$ & $250^{\mathrm{a}}$ & 176 \\
\hline & $\geq 3$ rd & 46 & $1974^{\mathrm{b}}$ & 645 & $34^{\mathrm{b}}$ & $6 \cdot 4$ & 27 & 4.9 & $284^{\mathrm{b}}$ & 193 \\
\hline \multirow[t]{2}{*}{ Health } & $1 \mathrm{st} / 2 \mathrm{nd}$ & 42 & 2024 & 634 & $34^{\mathrm{a}}$ & $6 \cdot 2$ & $26 \cdot 6$ & $4 \cdot 5$ & $311^{\mathrm{a}}$ & 192 \\
\hline & $\geq 3 \mathrm{rd}$ & 58 & 2058 & 671 & $35^{\mathrm{b}}$ & $6 \cdot 1$ & $27 \cdot 1$ & $5 \cdot 1$ & $233^{b}$ & 172 \\
\hline \multirow[t]{2}{*}{ Nutrition } & $1 \mathrm{st} / 2 \mathrm{nd}$ & 42 & 2017 & 633 & 34 & $5 \cdot 9$ & $26 \cdot 4^{\mathrm{a}}$ & 4.4 & $312^{\mathrm{a}}$ & 184 \\
\hline & $\geq 3 \mathrm{rd}$ & 58 & 2063 & 672 & 35 & $6 \cdot 3$ & $27 \cdot 2^{\mathrm{b}}$ & $5 \cdot 1$ & $232^{\mathrm{b}}$ & 178 \\
\hline \multirow[t]{2}{*}{ Cost } & $1 \mathrm{st} / 2 \mathrm{nd}$ & 18 & 2052 & 737 & 35 & 6.5 & $28 \cdot 1^{\mathrm{a}}$ & $5 \cdot 6$ & $202^{\mathrm{a}}$ & 158 \\
\hline & $\geq 3 \mathrm{rd}$ & 82 & 2043 & 638 & 34 & $6 \cdot 1$ & $26 \cdot 6^{\mathrm{b}}$ & 4.7 & $280^{\mathrm{b}}$ & 187 \\
\hline \multirow{2}{*}{ Convenience } & $1 \mathrm{st} / 2 \mathrm{nd}$ & 20 & 2059 & 663 & 35 & $5 \cdot 9$ & $27 \cdot 4$ & $5 \cdot 3$ & $210^{\mathrm{a}}$ & 165 \\
\hline & $\geq 3 \mathrm{rd}$ & 80 & 2040 & 653 & 34 & $6 \cdot 2$ & $26 \cdot 7$ & 4.7 & $279^{\mathrm{b}}$ & 187 \\
\hline
\end{tabular}

Values are means across low vs high rankings of motives. Significance determined using t-test. ${ }^{\text {ns }}$ non significant; ${ }^{\text {ab }}$ significant difference between $1^{\text {st }} / 2^{\text {nd }}$ and $3^{\text {rd }}$ ranking of motive at $\mathrm{P}<0 \cdot 05$. EI $=$ Energy Intake; BMI $=$ body mass index.

Hence dietary guidelines that are promoted on the basis of healthy eating alone will only appeal to a certain proportion of the population who are motived by health and nutrition. Guidelines should account for taste and cost drivers of food choice and promote the sensory aspects of healthy food choice and not solely health.

1. Wansink B \& Sobal J (2007) Environment and Behavior, 39, 106-123.

2. Roininen K, \& Tuorila H. (1999) Food Quality and Preference, 10, 357-365.

3. Zandstra EH, De Graaf C, \& Van Staveren WA (2001) Food Quality and Preference, 12, 75-82. 